\title{
Urinary sodium is positively associated with urinary free cortisol and total cortisol metabolites in a cross-sectional sample of Australian schoolchildren aged 5-12 years and their mothers
}

\author{
Susan J. Torres ${ }^{1}$, Carley Grimes ${ }^{1}$, Caryl A. Nowson ${ }^{1}$, Sisitha U. Jayasinghe ${ }^{1,2}$, Clinton R. Bruce ${ }^{1}$, \\ Shaun A. Mason ${ }^{1}$, Feng J. He ${ }^{3}$ and Anne I. Turner ${ }^{1}$ * \\ ${ }^{1}$ Institute for Physical Activity and Nutrition, School of Exercise and Nutrition Sciences, Deakin University, Geelong, \\ VIC 3220, Australia \\ ${ }^{2}$ Department of Physiology, University of Lausanne, Rue du Bugnon 7, 1005, Lausanne, Switzerland \\ ${ }^{3}$ Centre for Environmental and Preventative Medicine, Wolfson Institute of Preventative Medicine, Queen Mary University of \\ London, London EC1M 6BQ, UK
}

(Submitted 14 March 2018 - Final revision received 2 October 2018 - Accepted 3 October 2018)

\section{Abstract}

High $\mathrm{Na}$ intake and chronically elevated cortisol levels are independently associated with the development of chronic diseases. In adults, high $\mathrm{Na}$ intake is associated with high levels of urinary cortisol. We aimed to determine the association between urinary Na and $\mathrm{K}$ and urinary cortisol in a cross-sectional sample of Australian schoolchildren and their mothers. Participants were a sample of Australian children $(n$ 120) and their mothers ( $n$ 100) recruited through primary schools. We assessed $\mathrm{Na}, \mathrm{K}$, free cortisol and cortisol metabolites in one $24 \mathrm{~h}$ urine collection. Associations between $24 \mathrm{~h}$ urinary electrolytes and $24 \mathrm{~h}$ urinary cortisol were assessed using multilevel mixed-effects linear regression models. In children, urinary Na was positively associated with urinary free cortisol $(\beta=0 \cdot 31,95 \%$ CI $0 \cdot 19,0 \cdot 44)$ and urinary cortisol metabolites $(\beta=0 \cdot 006,95 \%$ CI 0.002, 0.010). Positive associations were also observed between urinary $\mathrm{K}$ and urinary free cortisol $(\beta=0.65$, $95 \% \mathrm{CI} 0 \cdot 23,1.07)$ and urinary cortisol metabolites $(\beta=0.02,95 \% \mathrm{CI} 0 \cdot 03,0 \cdot 031)$. In mothers, urinary Na was positively associated with urinary free cortisol $(\beta=0.23,95 \%$ CI $0 \cdot 01,0 \cdot 50)$ and urinary cortisol metabolites $(\beta=0.008,95 \%$ CI $0.0007,0 \cdot 016)$. Our findings show that daily Na and $\mathrm{K}$ intake were positively associated with cortisol production in children and their mothers. Investigation of the mechanisms involved and the potential impact of $\mathrm{Na}$ reduction on cortisol levels in these populations is warranted.

Key words: Sodium: Potassium: Dietary intakes: Urinary electrolytes: Cortisol: Children: Mothers

There is evidence that excessive $\mathrm{Na}$ intake is associated with the development of hypertension and CVD in adults ${ }^{(1)}$, and that modest reductions in $\mathrm{Na}$ intake can lead to a decrease in blood pressure in children ${ }^{(2)}$. Recent studies have also shown that $\mathrm{Na}$ intake is positively related to obesity in adults ${ }^{(3)}$ and children ${ }^{(4)}$, independent of energy intake. In most developed countries, adults consume too much $\mathrm{Na}$ and this has also been observed in children, with intakes far exceeding dietary recommendations $^{(5)} . \mathrm{K}$ is a nutrient known to have beneficial effects on health in adults, including reducing blood pressure and risk of stroke and CVD, reducing age-related bone loss and reduction of kidney stones ${ }^{(6)}$.

It has been suggested that a high-Na diet may lead to the development of chronic diseases via increased production of cortisol as measured in urine ${ }^{(7)}$. Cortisol, the main glucocorticoid in humans, is an important steroid hormone in the regulation of metabolism and stress, which is produced by activation of the hypothalamic-pituitary-adrenal axis ${ }^{(8)}$. Cortisol can also be produced in tissues by the conversion of inactive cortisone to active cortisol where it can have direct biological effects at a local level ${ }^{(9)}$. Elevated cortisol has been linked to the development of numerous diseases in adults, including CVD, type 2 diabetes and the metabolic syndrome ${ }^{(10)}$. In a large cross-sectional study of adult men and women, hair cortisol, as a marker of long-term cortisol exposure, was positively associated with weight, BMI and waist circumference, and in a retrospective longitudinal analysis was found to be associated with obesity over 4 years ${ }^{(11)}$. The potential detrimental effects of excess cortisol levels have also been observed in paediatric populations. For example, greater increases in salivary cortisol in response to mild psychological stress in children was associated with adverse effects on memory function ${ }^{(12)}$. Recent

Abbreviation: $11 \beta \mathrm{HSD}, 11 \beta$-hydroxysteroid dehydrogenase.

* Corresponding author: Dr A. I. Turner, email anne.turner@deakin.edu.au 
evidence shows that cortisol is elevated in children and adolescents with depression ${ }^{(13)}$ and in obese prepubertal girls ${ }^{(14)}$.

There is evidence in adults to suggest that $\mathrm{Na}$ intake is positively associated with urinary cortisol concentrations. For example, in experimental studies conducted in adults, urinary free cortisol increases after consuming high-Na diets of $320 \mathrm{mEq} / \mathrm{d}^{(15)}$ and $200 \mathrm{mmol} / \mathrm{d}^{(16)}$ and decreases after restricting $\mathrm{Na}$ intake to $20^{(17)}$ and $10 \mathrm{mmol} / \mathrm{d}^{(18)}$. While one study found no evidence of an association between $24 \mathrm{~h}$ urinary $\mathrm{Na}$ and cortisol levels, this study measured cortisol levels only in serum rather than urine ${ }^{(19)}$. These findings are consistent with those of Baudrand et al. ${ }^{(7)}$ who measured cortisol in both plasma and urine. These investigators showed that urinary free cortisol and total cortisol metabolite levels in urine, but not plasma, were significantly higher in participants with high $\mathrm{Na}$ intake compared with those with an adequate $\mathrm{Na}$ intake ${ }^{(7)}$. These latter two studies suggest that it is not sufficient to measure cortisol in plasma/serum as these levels remain well controlled within a stable homoeostatic range. Instead, it appears necessary to measure cortisol levels in urine. While the levels of cortisol in plasma would intuitively seem to be the most important, as these are what the tissues are exposed to, when cortisol are produced within tissues, it can have detrimental effects at a local level before entering the systemic circulation and being cleared rapidly by the kidney. Measures of both urinary free cortisol and total cortisol metabolites are necessary to provide a complete picture of urine cortisol excretion, which is thought to be indicative of overall daily cortisol production ${ }^{(7)}$. Although there is evidence of an association between $\mathrm{Na}$ intake and urinary cortisol in adults, no studies have examined this association in children.

Thus, the primary objective of this study was to test the hypothesis that $24 \mathrm{~h}$ urinary $\mathrm{Na}$ is positively associated with $24 \mathrm{~h}$ urinary free cortisol and total cortisol metabolites in a sample of Australian schoolchildren aged 5-12 years and their mothers. Given the known health benefits of higher $\mathrm{K}$ intake, and the lack of data available on $\mathrm{K}$ and cortisol in adults and children, we further hypothesised that children and their mothers would show a negative association between $24 \mathrm{~h}$ urinary $\mathrm{K}$ and urinary free cortisol and total cortisol metabolites. This was part of a larger cross-sectional study in which we have previously reported a positive association between $\mathrm{Na}$ intake and obesity risk in Australian schoolchildren ${ }^{(4)}$.

\section{Methods}

\section{Study design and participants}

In this study, we measured urinary free cortisol and cortisol metabolites in $24 \mathrm{~h}$ urine samples in a sub-group of primary schoolchildren and their mothers who had participated in the Salt and Other Nutrient Intakes in Children (SONIC) study, which included children and their parents sampled from primary schools located in Victoria, Australia from 2009 to 2013. A detailed description of the study protocol and the primary results have been reported previously ${ }^{(20,21)}$. The initial sample size for this study was determined by the number of mothers with available Na data, which was 107 mothers. If two or more children from one family had participated in the SONIC study, we randomly selected one child per mother to be included. A total of five mothers were subsequently excluded because cortisol data could not be obtained, but we chose to keep their child in the present study. As we wished to look at the association between urinary $\mathrm{Na}$ and urinary cortisol across the widest possible range of $\mathrm{Na}$ intakes in children, we included an additional seven children with $\mathrm{Na}$ levels $(249-310 \mathrm{mmol} / 24 \mathrm{~h}$ ) higher than the range of the already selected children (31-245 mmol/24 h) and six children with $\mathrm{Na}$ levels lower than this selected range $(13-30 \mathrm{mmol} / 24 \mathrm{~h})$. Therefore, our sample included 102 mother-child pairs and a total of 120 children.

The study was conducted according to the guidelines laid down in the Declaration of Helsinki. Mothers and children provided written informed consent before commencing the study, which was approved by the Deakin University Human Ethics Committee (Project no. EC 62-2009).

\section{Measures}

Socio-economic status (SES) was based on school postcode, as previously defined ${ }^{(4)}$.

$24 \mathrm{~h}$ urine collection. The $24 \mathrm{~h}$ urine collection protocol has been described elsewhere ${ }^{(4,21)}$. In brief, at the start of the $24 \mathrm{~h}$ urine collection, children and mothers were instructed to empty their bladder, discard this urine and note this as the start time of their collection. Following this, all urine voided was collected until the $24 \mathrm{~h}$ finish time. Urine samples were considered incomplete and not included in the final analysis if collection time was $<20$ or $>28 \mathrm{~h}$, total volume was $<300 \mathrm{ml}$, the participant reported missing $>1$ collection, or urinary creatinine for children were $<0 \cdot 1 \mathrm{mmol} / \mathrm{kg}$ body weight per $\mathrm{d}^{(21)}$. Mothers with suspected inaccurate urine collections (i.e. urinary creatinine $<4 \mathrm{mmol} / \mathrm{d}$ for women, or a $24 \mathrm{~h}$ urine collection of $<500 \mathrm{ml}$ ) were excluded.

Aliquots of urine $(2 \mathrm{ml})$ that were stored at $-80^{\circ} \mathrm{C}$ were thawed under room temperature and utilised for free cortisol and cortisol metabolite analyses.

\section{Urinary free cortisol analysis}

Concentrations of urinary free cortisol were measured using an ELISA (Diametra). A total of seven assays were conducted with the lowest detection sensitivity of $2.95 \mathrm{ng} / \mathrm{ml}$ at the $95 \%$ confidence limit. The intra-assay $\mathrm{CV}$ was $4.8 \%$ at $47 \mathrm{ng} / \mathrm{ml}$ and $8.0 \%$ at $287 \mathrm{ng} / \mathrm{ml}$. The inter-assay CV was $10 \cdot 8 \%$ at $47 \mathrm{ng} / \mathrm{ml}$ and $7.9 \%$ at $287 \mathrm{ng} / \mathrm{ml}$.

\section{Extraction of steroids and measurement of cortisol metabolites by GC-MS}

Steroids were extracted from urine samples and measured using GC-MS based on previously published methods ${ }^{(22)}$ with some modifications. Briefly, deuterated internal standards, tetrahydrocortisone- $\mathrm{D}_{5}$ and tetrahydrocortisol- $\mathrm{D}_{5}$ (Sigma Aldrich), were added to samples followed by hydrolysis, 
extraction and derivatisation steps described previously ${ }^{(22)}$. $\mathrm{N}$-dried samples were reconstituted in cyclohexane/pyridine/ hexamethyldisilazane $(98: 1: 1)$ and transferred to vials for GC-MS

The GC-MS system consisted of Agilent components: a 6890 GC, a 7683 automated sampler and a 5975C mass selective detector. A $30 \mathrm{~m} \times 0.25 \mathrm{~mm}$ (inner diameter) $\times 0.25 \mu \mathrm{m}$ capillary column (VF-Xms; Agilent Technologies) was used with helium as the carrier gas (flow rate $1.1 \mathrm{ml} / \mathrm{min}$ ). The GC oven programme consisted of an initial hold temperature of $70^{\circ} \mathrm{C}$ for $1.5 \mathrm{~min}$, a $25^{\circ} \mathrm{C} / \mathrm{min}$ ramp to $220^{\circ} \mathrm{C}$, a $2^{\circ} \mathrm{C} / \mathrm{min}$ ramp to $276^{\circ} \mathrm{C}$, a $25^{\circ} \mathrm{C} / \mathrm{min}$ ramp to $320^{\circ} \mathrm{C}$, and a final hold time for $3 \mathrm{~min}$ at $320^{\circ} \mathrm{C}$. Data recording and analysis occurred using MSD Chemstation software (Agilent Technologies). Endogenous cortisol metabolites, $\alpha$-cortolone, $\beta$-cortolone, $\alpha$-cortol, $\beta$-cortol, tetrahydrocortisone, tetrahydrocortisol and allo-tetrahydrocortisol and deuterated internal standards were identified using selective ion monitoring. External standard curves were run daily for each of the target metabolites for purposes of relative quantification. Each metabolite was quantitatively corrected for its own or its closest-related deuterated internal standard. The total cortisol metabolites in each sample were calculated as the sum of each individual cortisol metabolite concentration, corrected for the total urine collection volume.

\section{Urinary sodium and potassium analysis}

Returned $24 \mathrm{~h}$ urine samples were transported to an accredited commercial pathology laboratory (Dorevitch Pathology) for analysis. Urinary $\mathrm{Na}$ and $\mathrm{K}$ concentrations were assessed using indirect ion selective electrodes, and urinary creatinine concentration was assessed using the Jaffe reaction ${ }^{(23)}$ on the Siemens Advia 2400 analyser (Siemens Healthcare). Approximately $90-95 \%$ of ingested $\mathrm{Na}$ is excreted in urine ${ }^{(24)}$. Because of the high recovery of $\mathrm{Na}$ in urine, $24 \mathrm{~h}$ urine is considered the 'gold standard' method to determine dietary $\mathrm{Na}$ intake ${ }^{(25)}$. The CV for $\mathrm{Na}$ and $\mathrm{K}$ was $<1 \%$ and for creatinine it was $3.25 \%$. If the duration of the collection was not exactly $24 \mathrm{~h}$ but within 20-28 h, urinary electrolytes, creatinine, urinary free cortisol, urinary cortisol metabolites and total volume were standardised to a $24 \mathrm{~h}$ period (i.e. $(24 \mathrm{~h} /$ urine duration $(\mathrm{h})) \times$ urinary measure).

\section{Anthropometric measures}

Height and weight of children were measured by trained research staff following standard protocols ${ }^{(4,21)}$. BMI was calculated as weight $(\mathrm{kg})$ divided by height $(\mathrm{m})$ squared. BMI values were converted to age- and sex-adjusted BMI $z$ scores using the 2000 US Centers for Disease Control and Prevention growth charts ${ }^{(26,27)}$. No anthropometry data were available for the mothers.

\section{Statistical analysis}

Descriptive statistics (mean values and standard deviations or numbers and percentages) were calculated to describe the participant characteristics. Differences between children and mothers $24 \mathrm{~h}$ urinary electrolytes and $24 \mathrm{~h}$ urinary cortisol were assessed using the Mann-Whitney $U$ test. Multilevel mixedeffects linear regression was used to determine the association between urinary $\mathrm{Na}$ or urinary $\mathrm{K}$ and urinary free cortisol or total cortisol metabolites. All models included a random intercept for school. In children, unadjusted models and models adjusting for age, sex, urinary $\mathrm{Na}$ or urinary $\mathrm{K}$ are presented. In an additional model, we also adjusted for BMI $z$-score because obesity may influence the association between urinary electrolytes and urinary cortisol. In mothers, unadjusted models and models adjusting for age, urinary $\mathrm{Na}$ or urinary $\mathrm{K}$ were fitted. In addition, the associations were tested between mothers and children for urinary electrolytes and urinary cortisol. Model residuals were assessed for normality and heteroscedasticity using $\mathrm{Q}-\mathrm{Q}$ plots and plots of residuals against fitted values.

On the basis of prior research ${ }^{(7)}$, we estimated an effect size of $r^{2} 0.17$ for the relationship between urinary $\mathrm{Na}$ and urinary free cortisol and $r^{2} 0 \cdot 10$ for the relationship between urinary $\mathrm{Na}$ and urinary cortisol metabolites. Power analyses conducted separately for children $(n 120)$ and mothers ( $n$ 100) showed that we had over $90 \%$ power to detect these effects, for $\alpha=0 \cdot 05$. All statistical analysis, including power analysis, was conducted using SPSS 24.0 for Windows (SPSS Inc.) and STATA SE, version 15 (1985-2017; StataCorp).

\section{Results}

\section{Participants}

Table 1 shows the demographic characteristics and $24 \mathrm{~h}$ urinary electrolytes and cortisol for children and mothers. There was one mother excluded based on an extremely low urinary $\mathrm{Na}$ concentration $(10 \mathrm{mmol} / 24 \mathrm{~h},>3 \mathrm{sD}$ below the mean) and one mother excluded with an extremely high urinary free cortisol concentration ( $529 \mathrm{mmol} / 24 \mathrm{~h},>3 \mathrm{sD}$ above the mean). The final sample consisted of 120 children and 100 mothers. There was no difference in age, sex, SES or BMI $z$-score between those children in this sub-study compared with those in the original SONIC study (data not shown, $P>0.05$ for all ${ }^{(4)}$. Overall, $53 \%$ of children were girls and had an average age of 9.2 years. In total, $13 \%$ of children were either overweight or obese. With respect to $\mathrm{Na}$ intake in the children, urinary $\mathrm{Na}$ ranged from 13 to $310 \mathrm{mmol} / \mathrm{d}$ with a mean of $104 \mathrm{mmol} / \mathrm{d}$. There were forty-five $(38 \%)$ children who were at or below the recommended dietary $\mathrm{Na}$ upper level and seventy-five (63\%) children who exceeded the upper level (upper level: 4-8 years $60 \mathrm{mmol} / \mathrm{d}, 9-13$ years $86 \mathrm{mmol} / \mathrm{d})^{(28)}$. The average age of mothers was 41.7 years. In mothers, urinary $\mathrm{Na}$ ranged from 47 to $237 \mathrm{mmol} / \mathrm{d}$ with a mean of $121 \mathrm{mmol} / \mathrm{d}$. There were thirty-six (36\%) mothers who were at or below the recommended $\mathrm{Na}$ upper level for adults of $100 \mathrm{mmol} / \mathrm{d})^{(28)}$ and sixty-four (64\%) mothers who exceeded the upper level. Compared with children, the mothers had significantly higher levels of urinary electrolytes, urinary free cortisol and total cortisol metabolites (Table 1). 
Table 1. Descriptive characteristics of participants

(Mean values and standard deviations; numbers and percentages)

\begin{tabular}{|c|c|c|c|c|}
\hline \multirow[b]{2}{*}{ Characteristics } & \multicolumn{2}{|c|}{ Children ( $n$ 120) } & \multicolumn{2}{|c|}{ Mothers ( $n$ 100) } \\
\hline & Mean & SD & Mean & SD \\
\hline Age (years) & $9 \cdot 2$ & $2 \cdot 0$ & 41.7 & $5 \cdot 1$ \\
\hline Age range (years) & \multicolumn{2}{|c|}{$5 \cdot 0-12 \cdot 8$} & \multicolumn{2}{|c|}{$23 \cdot 3-52 \cdot 4$} \\
\hline \multicolumn{5}{|l|}{ Female } \\
\hline$n$ & \multicolumn{2}{|c|}{63} & \multicolumn{2}{|c|}{100} \\
\hline$\%$ & \multicolumn{2}{|c|}{53} & \multicolumn{2}{|c|}{100} \\
\hline BMI $\left(\mathrm{kg} / \mathrm{m}^{2}\right)$ & $17 \cdot 3$ & 3.0 & \multicolumn{2}{|c|}{ NA } \\
\hline BMI (z-score) & 0.1 & 1.0 & \multicolumn{2}{|c|}{ NA } \\
\hline \multicolumn{5}{|l|}{ Weight category } \\
\hline Underweight (\%) & \multicolumn{2}{|c|}{$10 \cdot 0$} & \multicolumn{2}{|c|}{ NA } \\
\hline Healthy weight (\%) & \multicolumn{2}{|c|}{$\begin{array}{l}76.7 \\
11.7\end{array}$} & \multicolumn{2}{|c|}{ NA } \\
\hline Overweight (\%) & \multirow{2}{*}{\multicolumn{2}{|c|}{11.7}} & \multicolumn{2}{|c|}{ NA } \\
\hline Obese (\%) & 1.7 & & \multicolumn{2}{|c|}{ NA } \\
\hline Urinary $\mathrm{Na}(\mathrm{mmol} / 24 \mathrm{~h})$ & $104 \cdot 2$ & $61 \cdot 8$ & 121.4 & $40 \cdot 1$ \\
\hline Urinary $\mathrm{K}(\mathrm{mmol} / 24 \mathrm{~h})$ & $46 \cdot 8$ & $18 \cdot 5$ & 67.7 & $18 \cdot 3$ \\
\hline Urinary creatinine $(\mathrm{mmol} / 24 \mathrm{~h})$ & 5.4 & $2 \cdot 2$ & $10 \cdot 1$ & $2 \cdot 2$ \\
\hline Urinary free cortisol (nmol/24h) & $96 \cdot 2$ & $45 \cdot 8$ & 114.8 & 49.0 \\
\hline Total cortisol metabolites (mg/24 h) & 3.0 & 1.5 & 4.3 & 1.6 \\
\hline
\end{tabular}

NA, not available.

${ }^{*} P<0.05$ (Mann-Whitney $U$ test).

(a)

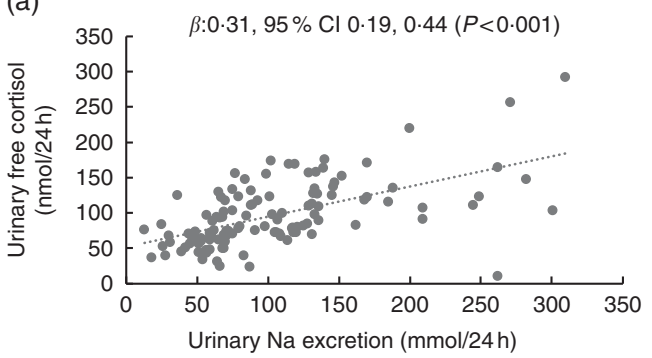

(c)

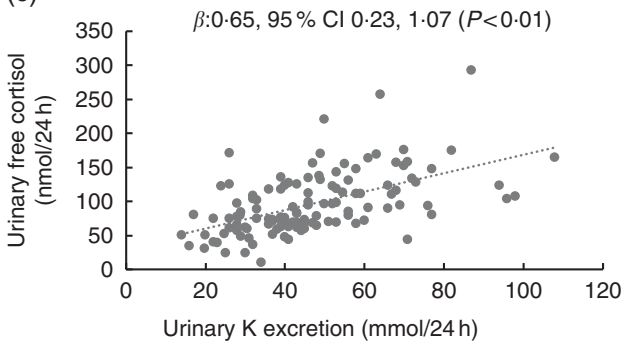

(b)

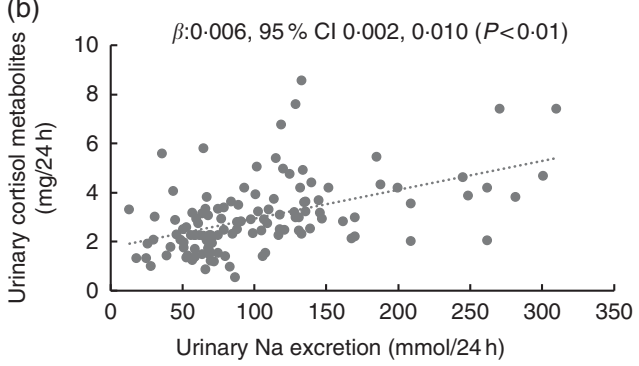

(d)

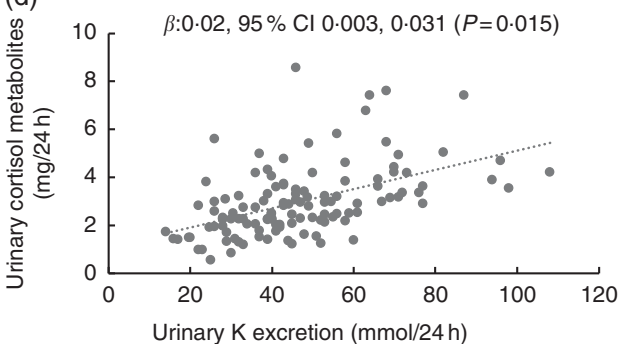

Fig. 1. Scatterplots for children's $24 \mathrm{~h}$ urinary electrolytes and $24 \mathrm{~h}$ urinary cortisol $(n 120)$. Scatterplots for (a) urinary sodium and urinary free cortisol, (b) urinary sodium and urinary cortisol metabolites, (c) urinary potassium and urinary free cortisol, (d) urinary potassium and urinary cortisol metabolites. Data were analysed with multilevel mixed-effects linear regressions adjusted for age, sex and BMl z score. In addition, adjusted for urinary potassium (a) and (b), and urinary sodium (c) and (d).

\section{Associations between urinary electrolytes and urinary cortisol}

Fig. 1 shows scatterplots for children's $24 \mathrm{~h}$ urinary electrolytes and urinary cortisol and cortisol metabolites. Table 2 shows the multilevel mixed-effects linear regression models for children with urinary electrolytes as the independent variables and urinary free cortisol and urinary cortisol metabolites as the dependent variables. In children, urinary $\mathrm{Na}$ and $\mathrm{K}$ were both positively associated with urinary free cortisol and urinary cortisol metabolites, and this relationship persisted after adjusting for relevant confounders (age, sex, urinary Na, urinary $\mathrm{K}$ and BMI $z$-score). Results from the fully adjusted models show that a $1 \mathrm{mmol} / 24 \mathrm{~h}$ increase in urinary $\mathrm{Na}$ was related to a $0.31(95 \% \mathrm{CI} 0 \cdot 19,0.44) \mathrm{nmol} / 24 \mathrm{~h}$ higher urinary free cortisol, and a $1 \mathrm{mmol} / 24 \mathrm{~h}$ increase in urinary $\mathrm{K}$ was related to a 0.65 (95\% CI 0.23, 1.07) nmol/24 h higher urinary free cortisol (Fig. 1). There was no evidence of an association between $\mathrm{Na}: \mathrm{K}$ ratio and either urinary free cortisol or urinary cortisol metabolites (data not shown).

In mothers, urinary $\mathrm{Na}$ was positively associated with urinary free cortisol and cortisol metabolites in both the unadjusted and 
Table 2. The association between urinary electrolytes and urinary cortisol in schoolchildren and mothers (Regression coefficients and $95 \%$ confidence intervals)

\begin{tabular}{|c|c|c|c|c|c|c|}
\hline & \multicolumn{3}{|c|}{ Urinary free cortisol } & \multicolumn{3}{|c|}{ Urinary cortisol metabolites } \\
\hline & $\beta$ & $95 \% \mathrm{Cl}$ & $P$ & $\beta$ & $95 \% \mathrm{Cl}$ & $P$ \\
\hline \multicolumn{7}{|l|}{ Children (n 120) } \\
\hline \multicolumn{7}{|l|}{ Urinary $\mathrm{Na}$} \\
\hline Model $1^{*}$ & 0.43 & $0.32,0.54$ & $<0.001$ & 0.01 & $0.008,0.015$ & $<0.001$ \\
\hline Model $2 \dagger$ & 0.29 & $0.17,0.40$ & $<0.001$ & 0.006 & $0.003,0.010$ & $<0.001$ \\
\hline Model $3 \ddagger$ & 0.31 & $0.19,0.44$ & $<0.001$ & 0.006 & $0.002,0.010$ & $<0.01$ \\
\hline \multicolumn{7}{|l|}{ Urinary $\mathrm{K}$} \\
\hline Model $1^{*}$ & 1.36 & $0.99,1.73$ & $<0.001$ & 0.04 & $0.03,0.05$ & $<0.001$ \\
\hline Model $2 \S$ & 0.60 & $0.18,1.02$ & $<0.01$ & 0.02 & $0.004,0.003$ & 0.01 \\
\hline Model 3\| & 0.65 & $0.23,1.07$ & $<0.01$ & 0.02 & $0.003,0.031$ & 0.015 \\
\hline \multicolumn{7}{|l|}{ Mothers $(n 100)$} \\
\hline \multicolumn{7}{|l|}{ Urinary $\mathrm{Na}$} \\
\hline Model $1^{*}$ & 0.26 & $0.03,0.50$ & 0.026 & 0.009 & $0.002,0.017$ & 0.012 \\
\hline Model 2ף & 0.23 & $0.01,0.50$ & 0.042 & 0.008 & $0.0007,0.016$ & 0.032 \\
\hline \multicolumn{7}{|l|}{ Urinary $\mathrm{K}$} \\
\hline Model $1^{*}$ & 0.32 & $-0.20,0.83$ & 0.233 & 0.017 & $-0.0001,0.033$ & 0.047 \\
\hline Model $2^{\star *}$ & 0.14 & $-0.41,0.70$ & 0.618 & 0.015 & $-0.002,0.032$ & 0.087 \\
\hline
\end{tabular}

* Model 1: unadjusted.

$\dagger$ Model 2: adjusted for age, sex and urinary $\mathrm{K}$.

$\ddagger$ Model 3: adjusted for age, sex, urinary $\mathrm{K}$ and BMI $z$ score.

$\S$ Model 2: adjusted for age, sex and urinary $\mathrm{Na}$.

|| Model 3: adjusted for age, sex, urinary $\mathrm{Na}$ and $\mathrm{BMI} z$ score.

II Model 2: adjusted for age and urinary K ( $n 94$ included in analysis).

${ }^{\star \star}$ Model 2: adjusted for age and urinary $\mathrm{Na}$ ( $n 94$ included in analysis).
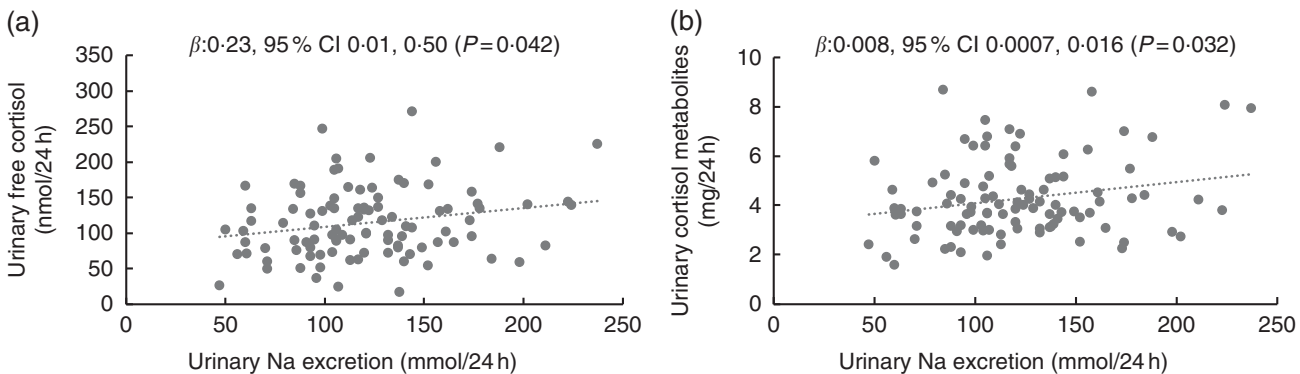

(c)

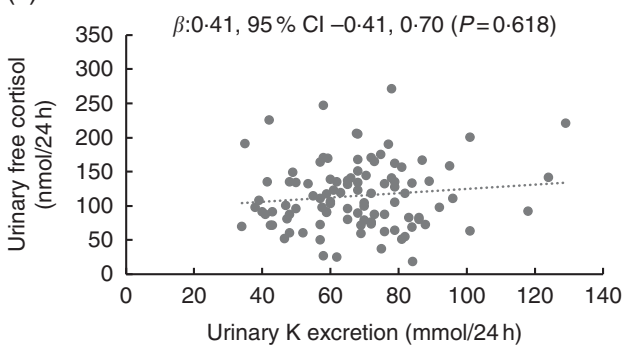

(d)

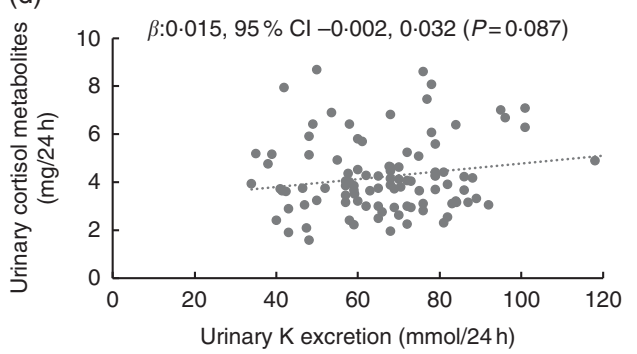

Fig. 2. Scatterplots for mother's $24 \mathrm{~h}$ urinary electrolytes and $24 \mathrm{~h}$ urinary cortisol $(n$ 100). Scatterplots for (a) urinary sodium and urinary free cortisol, (b) urinary sodium and urinary cortisol metabolites, (c) urinary potassium and urinary free cortisol, (d) urinary potassium and urinary cortisol metabolites. Data were analysed with multilevel mixed-effects linear regressions adjusted for age. In addition, adjusted for urinary potassium (a) and (b), and urinary sodium (c) and (d).

adjusted models (Table 2 and Fig. 2). Urinary K was positively associated with urinary cortisol metabolites in the unadjusted model but not in the adjusted model and urinary $\mathrm{K}$ was not associated with urinary free cortisol in unadjusted or adjusted models. In mothers, urinary $\mathrm{Na}$ was positively associated with urinary $\mathrm{K}(r 0 \cdot 266, P<0 \cdot 05)$.

Within mother-child dyads, urinary $\mathrm{Na}$, free cortisol and cortisol metabolites were positively associated $(P<0.05)$ between mothers and children's, but urinary K was not (Table 3).

\section{Discussion}

Among a sample of Australian schoolchildren, we have reported novel data for the first time that higher $24 \mathrm{~h}$ urinary $\mathrm{Na}$ and $\mathrm{K}$ levels were associated with higher $24 \mathrm{~h}$ urinary free cortisol and urinary cortisol metabolites. In mothers, urinary $\mathrm{Na}$ was positively associated with both urinary free cortisol and cortisol metabolites, while urinary $\mathrm{K}$ was not associated with urinary free cortisol or cortisol metabolites. Associations in children 
Table 3. Pairwise associations between urinary electrolytes and urinary cortisol in mother-child dyads ( $n$ 100) (Regression coefficients and 95\% confidence intervals)

\begin{tabular}{lllrrr}
\hline Outcome & Predictor & & \multicolumn{3}{c}{ Unadjusted model } \\
\cline { 5 - 7 } \cline { 5 - 6 } Child & Mother & & $\beta$ & $95 \% \mathrm{Cl}$ & \multicolumn{1}{c}{$P$} \\
\hline $\mathrm{Na}$ & $\mathrm{Na}$ & & 0.25 & $0.06,0.43$ & $<0.001$ \\
$\mathrm{~K}$ & $\mathrm{~K}$ & & 0.06 & $-0.11,0.22$ & 0.514 \\
Urinary free cortisol & Urinary free cortisol & & 0.26 & $0.11,0.41$ & $<0.001$ \\
Urinary cortisol metabolites & Urinary cortisol metabolites & & 0.19 & $0.03,0.36$ & 0.023 \\
\hline
\end{tabular}

remained after adjusting for age, sex, BMI $z$ score, and urinary $\mathrm{Na}$ or urinary K. Overall, the magnitude of the associations was greatest in the children. We also found that urinary $\mathrm{Na}$, free cortisol and cortisol metabolites were positively associated between children and mothers. It should be noted that causation cannot be established due to the cross-sectional nature of this study.

The level of urinary free cortisol in the children in the present study was similar to that in a population of obese children ${ }^{(29)}$, but higher than that in a population of healthy children ${ }^{(30)}$. Urinary free cortisol levels in the mothers in the present study were similar to those reported by Baudrand et al. ${ }^{(7)}$, however, cortisol metabolite levels were lower. Differences between studies may reflect inter-laboratory differences in methodologies, which has been reported in the analysis of hair cortisol concentrations $^{(31)}$

In the present study, our findings suggest for children that a high-Na diet is associated with an increase in daily production of cortisol. As previously reported, elevated cortisol levels have been linked to the development of chronic diseases in paediatric populations ${ }^{(12-14)}$. Our findings show that dietary $\mathrm{Na}$ appears to be a factor modifying cortisol production in both paediatric and adult populations. Our findings in mothers are consistent with evidence from studies in adults where high $\mathrm{Na}$ intake was also found to be positively associated with free urinary cortisol and urinary cortisol metabolites ${ }^{(7)}$. Likewise, in two studies in men that went from a low-Na $(10 \mathrm{mmol} / \mathrm{d})$ to high-Na diet $(200 \mathrm{mmol} / \mathrm{d})$, urinary cortisol increased by $65 \mathrm{nmol} / \mathrm{d}^{(16)}$ and $20 \mu \mathrm{g} / \mathrm{d}^{(18)}$. Although there is evidence to suggest $\mathrm{Na}$ intake is linked to cortisol production, the precise mechanisms remain to be elucidated. The main pathways of cortisol metabolism include two isoforms of the $11 \beta$-hydroxysteroid dehydrogenase (11 $\beta \mathrm{HSD}), 11 \beta \mathrm{HSD} 1$ and $11 \beta \mathrm{HSD} 2$, which are found in many human tissues ${ }^{(9)}$. 11 $\beta$ HSD1 converts inactive cortisone to cortisol and $11 \beta \mathrm{HSD} 2$ inactivates cortisol to cortisone. In rats fed a high salt diet, gene expression of $11 \beta \mathrm{HSD} 1$ increased in adipose tissue, resulting in greater production of the active hormone corticosterone (the main glucocorticoid found in rodents), providing support for how $\mathrm{Na}$ might influence cortisol secretion ${ }^{(32)}$. Currently, there is no evidence for an equivalent mechanism in a human model.

Our findings that urinary $\mathrm{K}$ was positively associated with urinary free cortisol and cortisol metabolites in children are novel as this has not been reported before in this population group. However, these findings were contrary to our hypothesis, where we predicted a negative association between urinary $\mathrm{K}$ and urinary free cortisol and total cortisol metabolites based on the reported health benefits of K. Nevertheless, feeding studies in rats have investigated a potential mechanism for how dietary $\mathrm{K}$ intake might influence corticosterone levels. Feeding rats a diet high in potassium chloride resulted in increased production of $11 \beta \mathrm{HSD} 2$ protein in the renal distal tubules, catalysing the conversion of the active corticosterone to the inactive 11-dehydrocorticosterone ${ }^{(33)}$. This results in greater specificity for renal distal tubule mineralocorticoid receptors to aldosterone, thereby promoting aldosterone-induced $\mathrm{K}$ excretion. In contrast, Thompson et al. ${ }^{(34)}$ found that a high-K diet was associated with reduced renal $11 \beta \mathrm{HSD} 2$ activity in rats, thus, enhancing the access of glucocorticoids to the mineralocorticoid receptor to promote urinary $\mathrm{K}$ excretion. While these two studies show that K may be involved in $11 \beta \mathrm{HSD} 2$ regulation in the renal distal tubule, and therefore glucocorticoid excretion, the discordant findings suggest that further research is required in this area. Further studies are needed to determine the relevant mechanisms present in humans and any potential physiological or health implications.

It is important to consider the clinical relevance of our findings. We found that $1 \mathrm{mmol} / 24 \mathrm{~h}$ of urinary Na was related to a $0.31 \mathrm{nmol} / 24 \mathrm{~h}$ higher urinary free cortisol and that $1 \mathrm{mmol} / 24 \mathrm{~h}$ of urinary $\mathrm{K}$ was related to a $0.65 \mathrm{nmol} / 24 \mathrm{~h}$ higher urinary free cortisol. While reference ranges for cortisol are available for the diagnosis of clinical conditions such as Cushing's syndrome ${ }^{(35)}$, clinically meaningful levels for cortisol in terms of biological outcomes for non-clinical populations are not well understood. Studies in adults have found that decreasing Na by $180 \mathrm{mmol} /$ $24 \mathrm{~h}$ reduced urinary free cortisol by $40^{(17)}$ and $61 \mathrm{nmol} / 24 \mathrm{~h}^{(18)}$. It is not likely, however, that such large reductions in Na would be achievable in the general population. In the present study, the average $\mathrm{Na}$ intake in the children was $104 \mathrm{mmol} / \mathrm{d}$ (compared with an upper level of $86 \mathrm{mmol} / \mathrm{d}, 9-13$ years) and the average $\mathrm{Na}$ intake in the mothers was $121 \mathrm{mmol} / \mathrm{d}$ (compared with an upper level of $100 \mathrm{mmol} / \mathrm{d})^{(28)}$. Overall, clinically meaningful reductions in urinary free cortisol are not well understood in paediatric or adult populations, therefore it is difficult to recommend a reduction in urinary $\mathrm{Na}$ and $\mathrm{K}$; further research in this area is warranted.

In the present study, we found that urinary free cortisol and cortisol metabolites were positively associated between children and mothers. This is consistent with results from a study that found high maternal hair cortisol was strongly associated with their infant's evening salivary cortisol levels ${ }^{(36)}$. In a sample of mothers and their children living in socioeconomically disadvantaged neighbourhoods, hair cortisol levels were also strongly positively associated between mothers and their 
children $^{(37)}$. Similarly, Pratt et al. ${ }^{(38)}$ reported concordance for diurnal cortisol secretion between mothers and their 6-year-old children. Tarullo et al. ${ }^{(36)}$ have proposed that this physiological concordance between mother and child has an evolutionary basis, such that having a similar response is adaptive when facing the same external risk.

There are limitations associated with this study, which must be considered when interpreting the findings. The crosssectional design of the study prevents the detection of causal relationships between dietary electrolyte intake and cortisol levels. We did not obtain any anthropometric measures in the mothers, so we were unable to adjust for these in the regression analyses. While the association between $\mathrm{Na}$ or $\mathrm{K}$ and cortisol may be influenced by the types of foods and nutrients consumed by the children and mothers, we were unable to assess this in our study. The convenience sample of schoolchildren potentially limits the generalisability of the findings to a wider population. We only assessed mothers in this study as the relationship between urinary electrolytes and urinary cortisol and cortisol metabolites between mother and child may differ to father and child. A strength of this study was that both urinary cortisol and cortisol metabolites were measured to fully characterise cortisol production.

In conclusion, in a population of schoolchildren and their mothers, this study has shown that high $\mathrm{Na}$ and $\mathrm{K}$ intake is associated with increased production of cortisol. The negative health implications of elevated cortisol exposure are well documented. Future research should include metabolic studies to investigate mechanisms that might be involved and the effect of $\mathrm{Na}$ reduction on cortisol levels in these target populations.

\section{Acknowledgements}

The authors thank Dr Catherine Huggins for her early work in securing project funding. The authors acknowledge the Victorian Department of Early Childhood and Development for their support in allowing this study to be conducted within the government school sector. The authors thank all schools, children and mothers who participated in the study.

This study was funded by a National Heart Foundation of Australia Grant-in-Aid (G 10 M 5021), a Helen MacPherson Smith Trust Fund Project Grant (6002), a Deakin University Faculty of Health Research Development Grant and by seed funding from Deakin University's Institute for Physical Activity and Nutrition. C. R. B. is supported by an Australian Research Council Future Fellowship (FT160100017).

C. G., C. A. N. and F. J. H. designed and conducted the original SONIC study. A. I. T., S. J. T. and C. A. N. designed and conducted this salt and cortisol sub-study including securing project funding. S. U. J. was responsible for the free urinary cortisol analysis. C. R. B. and S. A. M. were responsible for the urinary cortisol metabolite analysis. S. J. T. analysed the data and drafted the manuscript. All authors critically reviewed the manuscript and read and approved the final version.

None of the authors had a conflict of interest.

\section{References}

1. Kotchen TA, Cowley Jr AW \& Frohlich ED (2013) Salt in health and disease - a delicate balance. $N$ Engl J Med 368, 1229-1237.

2. He FJ \& MacGregor GA (2006) Importance of salt in determining blood pressure in children: meta-analysis of controlled trials. Hypertension 48, 861-869.

3. Ma Y, He FJ \& MacGregor GA (2015) High salt intake: independent risk factor for obesity? Hypertension $\mathbf{6 6}$, 843-849.

4. Grimes CA, Riddell LJ, Campbell KJ, et al. (2016) 24-h urinary sodium excretion is associated with obesity in a crosssectional sample of Australian schoolchildren. Br J Nutr $\mathbf{1 1 5}$, 1071-1079.

5. Brown IJ, Tzoulaki I, Candeias V, et al. (2009) Salt intakes around the world: implications for public health. Int J Epidemiol 38, 791-813.

6. Weaver CM (2013) Potassium and health. Adv Nutr 4, 368S-377S.

7. Baudrand R, Campino C, Carvajal CA, et al. (2014) High sodium intake is associated with increased glucocorticoid production, insulin resistance and metabolic syndrome. Clin Endocrinol 80, 677-684.

8. Folkow B (1997) Physiological aspects of the "defence" and "defeat" reactions. Acta Physiol Scand Suppl 640, 34-37.

9. Tomlinson JW \& Stewart PM (2001) Cortisol metabolism and the role of 11beta-hydroxysteroid dehydrogenase. Best Pract Res Clin Endocrinol Metab 15, 61-78.

10. Chrousos GP (2009) Stress and disorders of the stress system. Nat Rev Endocrinol 5, 374-381.

11. Jackson SE, Kirschbaum C \& Steptoe A (2017) Hair cortisol and adiposity in a population-based sample of 2,527 men and women aged 54 to 87 years. Obesity 25, 539-544.

12. Heffelfinger AK \& Newcomer JW (2001) Glucocorticoid effects on memory function over the human life span. Dev Psychopathol 13, 491-513.

13. Stetler C \& Miller GE (2011) Depression and hypothalamicpituitary-adrenal activation: a quantitative summary of four decades of research. Psychosom Med 73, 114-126.

14. Papafotiou C, Christaki E, van den Akker EL, et al. (2017) Hair cortisol concentrations exhibit a positive association with salivary cortisol profiles and are increased in obese prepubertal girls. Stress 20, 217-222.

15. Wambach G, Bleienheuft C \& Bonner G (1986) Sodium loading raises urinary cortisol in man. J Endocrinol Invest 9, 257-259.

16. Litchfield WR, Hunt SC, Jeunemaitre X, et al. (1998) Increased urinary free cortisol: a potential intermediate phenotype of essential hypertension. Hypertension 31, 569-574.

17. Lewicka S, Nowicki M \& Vecsei P (1998) Effect of sodium restriction on urinary excretion of cortisol and its metabolites in humans. Steroids 63, 401-405.

18. Chamarthi B, Kolatkar NS, Hunt SC, et al. (2007) Urinary free cortisol: an intermediate phenotype and a potential genetic marker for a salt-resistant subset of essential hypertension. J Clin Endocrinol Metab 92, 1340-1346.

19. Afsar B \& Ay M (2014) The relationships between cortisol levels, insulin levels, and thyroid hormones with 24-h urinary sodium excretion in never treated essential hypertensive patients. ARYA Atheroscler 10, 159-163.

20. Grimes CA, Riddell LJ, Campbell KJ, et al. (2017) Dietary intake and sources of sodium and potassium among Australian schoolchildren: results from the cross-sectional Salt and Other Nutrients in Children (SONIC) study. BMJ Open 7, e016639. 
21. Grimes CA, Baxter JR, Campbell KJ, et al. (2015) Crosssectional study of 24-hour urinary electrolyte excretion and associated health outcomes in a convenience sample of australian primary schoolchildren: the Salt and Other Nutrients in Children (SONIC) study protocol. JMIR Res Protoc 4, e7.

22. Honour JW (1997) Steroid profiling. Ann Clin Biochem 34, 32-44.

23. Jaffe M (1886) Ueber den Niederschlag, welchen Pikrinsäure in normalem Harn erzeugt und über eine neue Reaction des Kreatinins (About the precipitate, which picric acid produced in normal urine and a new reaction of creatinine). $Z$ Physiol Chem 10, 391-400.

24. Bates CJ, Thurnham DI, Bingham SA, et al. (1997) Biochemical markers of nutrient intake. In Design Concepts in Nutritional Epidemiology, 2nd ed., pp. 170-240 [BM Margetts and M Nelson, editors]. Oxford: Oxford University Press Inc.

25. World Health Organization (2010) Strategies to Monitor and Evaluate Population Sodium Consumption and Sources of Sodium in the Diet. Geneva: World Health Organization.

26. Cole TJ, Flegal KM, Nicholls D, et al. (2007) Body mass index cut offs to define thinness in children and adolescents: international survey. BMJ 335, 194.

27. Cole TJ, Bellizzi MC, Flegal KM, et al. (2000) Establishing a standard definition for child overweight and obesity worldwide: international survey. BMJ 320, 1240-1243.

28. Department of Health and Ageing, National Health and Medical Research Council (2006) Nutrient Reference Values for Australia and New Zealand. Including Recommended Dietary Intakes. Canberra: Commonwealth of Australia.

29. Reinehr T, Kulle A, Wolters B, et al. (2014) Relationships between 24-hour urinary free cortisol concentrations and metabolic syndrome in obese children. J Clin Endocrinol Metab 99, 2391-2399.
30. Shi L, Berkemeyer S, Buyken AE, et al. (2010) Glucocorticoids and body fat associated with renal uric acid and oxalate, but not calcium excretion, in healthy children. Metabolism 59, 134-139.

31. Stalder T, Steudte-Schmiedgen S, Alexander N, et al. (2017) Stress-related and basic determinants of hair cortisol in humans: a meta-analysis. Psychoneuroendocrinology 77, 261-274.

32. Usukura M, Zhu A, Yoneda T, et al. (2009) Effects of a highsalt diet on adipocyte glucocorticoid receptor and 11-beta hydroxysteroid dehydrogenase 1 in salt-sensitive hypertensive rats. Steroids 74, 978-982.

33. Hermans JJ, Fischer MA, Schiffers PM, et al. (1999) High dietary potassium chloride intake augments rat renal mineralocorticoid receptor selectivity via 11beta-hydroxysteroid dehydrogenase. Biochim Biophys Acta 1472, 537-549.

34. Thompson A, Bailey MA, Michael AE, et al. (2000) Effects of changes in dietary intake of sodium and potassium and of metabolic acidosis on 11beta-hydroxysteroid dehydrogenase activities in rat kidney. Exp Nephrol 8, 44-51.

35. Pappachan JM, Hariman C, Edavalath M, et al. (2017) Cushing's syndrome: a practical approach to diagnosis and differential diagnoses. J Clin Pathol 70, 350-359.

36. Tarullo AR, St John AM \& Meyer JS (2017) Chronic stress in the mother-infant dyad: maternal hair cortisol, infant salivary cortisol and interactional synchrony. Infant Behav Dev $\mathbf{4 7}$, 92-102.

37. Olstad DL, Ball K, Wright C, et al. (2016) Hair cortisol levels, perceived stress and body mass index in women and children living in socioeconomically disadvantaged neighborhoods: the READI study. Stress 19, 158-167.

38. Pratt M, Apter-Levi Y, Vakart A, et al. (2017) Mother-child adrenocortical synchrony; moderation by dyadic relational behavior. Horm Behav 89, 167-175. 